\title{
Plasma Responses and Pancreatic Content of Pancreatic Polypeptide, Glucagon and Insulin in Alloxan Diabetic and Normal Dogs and Their Immuno- histological Studies
}

\author{
Yoshimasa TASAKA, Yukiko INOUE, KoJi MARUMO \\ AND YUKIMASA HIRATA \\ Diabetes Center, Tokyo Women's Medical College \\ Shinjuku-ku, Kawada-cho 10, Tokyo
}

\begin{abstract}
Responses of plasma pancreatic polypeptide (PP), glucagon (IRG) and insulin (IRI) after administration of beef soup were studied in normal and alloxan diabetic dogs and their regional content in the pancreas was determined in normal and four or twelve weeks alloxan diabetic dogs. Plasma PP levels of the diabetic dogs were significantly higher than those of the normal dogs and they increased after beef soup administration in both groups. Higher levels of IRG were also found in the diabetic dogs, although IRG increased significantly after beef soup ingestion only in normal dogs. The amounts of PP in the pancreas of normal and diabetic dogs were greatest at the uncinate process, followed in order by the head, body and tail. The IRG content in the pancreas was highest at the tail and lowest at the uncinate process in both dogs. The differences in both PP and IRG in pancreas between normal and diabetic dogs kept in a poor metabolic state for one or three months were not significant in any region of the pancreas. Immunocytochemical studies also suggested these findings. These results show that, irrespective of high plasma levels of PP and IRG in the diabetic dogs, their levels in the pancreas did not change significantly as also indicated by histological studies.
\end{abstract}

It has been already reported that plasma pancreatic polypeptide (PP) levels in diabetic subjects rise not only during the fasting state (Floyd et al., 1977; Tsuda et al., 1980; Bergen et al., 1981), but also during diabetic ketoacidosis (Skare et al., 1980) or after ingestion of beef or a test meal (Floyd et al., 1977; Bergen et al., 1981). Morphologically Gepts et al. (1977) reported that the PP cells in the islets of the juvenile diabetic pancreas show a hyperfunctioning state, but

Received October 5, 1983 recently there appeared some reports conflicting with this finding (Stefan et al., 1982; Klöppel and Drenck, 1983). Till now there have been no comparative studies of pancreatic hormonal content in diabetic and normal pancreas. We have already reported that there is no significant difference in the PP content either in the head or tail of the pancreas in diabetic subjects in contrast to that in nondiabetics (Tasaka et al., 1983). Since the influence of diabetic treatment on the hormonal content of the pancreas cannot be ignored when autopsied human dia- 
betic pancreas is used, pancreatic PP, IRG (immunoreactive glucagon) and IRI (immunoreactive insulin) content was investigated in alloxan diabetic dogs together with their plasma response after ingestion of beef soup, and moreover immunohistological studies have been done.

\section{Materials and Methods}

Male mongrel dogs weighing from ten to eighteen $\mathrm{kg}$ were used for the experiment. The dogs were made diabetic by the iv injection of alloxan $100 \mathrm{mg} / \mathrm{kg}$ in the fasting state, and they were kept in a poor diabetic metabolic state for four weeks or twelve weeks almost without insulin treatment. For the beef soup ingestion test, warmed Campbell beef soup (Campbell Soup Company. Camden, J. J., U.S. A.) was administered to pentobarbital-anesthetized dogs through a gastric tube in the amount of $156 \mathrm{~g} / 10$ $\mathrm{kg}$ body weight (total $108 \mathrm{kcal}$ : protein $30.6 \mathrm{kcal}$, fat $22.5 \mathrm{kcal}$, carbohydrate $55 \mathrm{kcal}$ ) diluted with half its volume of water. In the experiment on water loading, the same total volume of water was administered to the normal dog. Blood was drawn into a test tube containing EDTA and Trasylol $(500 \mathrm{U} / \mathrm{ml}$ of blood) from the forearm vein at $0,5,10,15,30,45,60,90,120$ and 180 min after ingestion of the meal, and centrifuged. The plasma was frozen at $-20^{\circ} \mathrm{C}$ until hormonal immunoassay. After removal of arterial blood through a cannula inserted into the femoral artery, the pancreas was dissected out. The pancreas pieces were taken from the uncinate process, head, body and tail, and were extracted with acid ethanol (Hayashi et al., 1977; Tasaka et al., 1981) and the amounts of PP, IRG and IRI in the pancreas were determined by immunoassay. IRI in the extract of the pancreas and in the plasma was determind by the twoantibody immnoassay of Morgan and Lazarow (1963) with dog insulin as standard. PP was measured by two-antibody immunoassay (Chance et al., 1979). The anti-PP serum used for PP assay was kindly donated by Dr. R. E. Chance (Eli Lilly \& Co., Indianapolis, Ind. Lot. 6151054B-248-19). This assay system detected changes in plasma HPP of $32 \mathrm{pg} / \mathrm{ml}$ with $95 \%$ accuracy. Recovery in the serum was $84 \%$ and $91 \%$ following the addition of $200 \mathrm{pg}$ and 400 pg of HPP. The between-assay coefficients of variation found in 5 consecutive assays at concentrations of 200 and $400 \mathrm{pg} / \mathrm{ml}$ were 11.9 and $15.6 \%$. IRG in the extract and in the plasma was measured by the polyethylene glycol method (Henquin et al., 1974), using $30 \mathrm{k}$ antiglucagon serum (Hoechst Agent, Tokyo), where changes in plasma IRG of $20 \mathrm{pg} / \mathrm{ml}$ were able to be detected with $95 \%$ accuracy. The between-assay coefficient of variation found in 5 consecutive assays was between 1.6 and $7.5 \%$. The plasma glucose was determind by the glucose oxidase method using autoanalyser. Statistical analysis was performed by Student's $t$-test and probability of less than $5 \%$ was considered to be significant.

\section{Results}

\section{Plasma Glucose, PP, IRG and IRI after Beef Soup Ingestion Test.}

The plasma response of glucose, PP, IRG and IRI after the beef soup ingestion test in normal and alloxan diabetic dogs was determined. The plasma glucose level of normal dogs was $79 \pm 1 \mathrm{mg} / \mathrm{dl} \quad($ Mean \pm SE) in the fasting state and was increased significantly $(\mathrm{p}<0.02)$ to $86 \pm 3 \mathrm{mg} / \mathrm{dl} 45 \mathrm{~min}$ after soup ingestion $(\mathrm{p}<0.05$ at $30 \mathrm{~min}$ and $60 \mathrm{~min}$ ) (Figure 1). In diabetic dogs, the fasting plasma glucose was $303 \pm 28 \mathrm{mg} / \mathrm{dl}$, peaking not significantly to $332 \pm 21 \mathrm{mg} / \mathrm{dl}$ at $180 \mathrm{~min}$, and these values were significantly higher than those of normal dogs $(\mathrm{p}<0.01)$.

The plasma PP levels of normal dogs

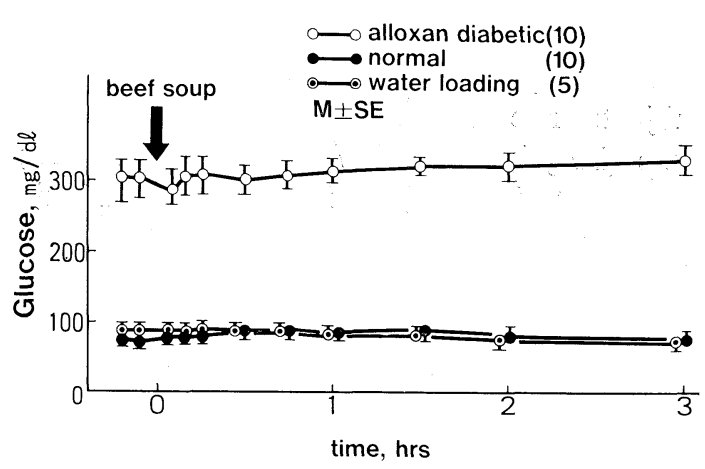

Fig. 1. Changes in plasma glucose levels after beef soup or water ingestion. 


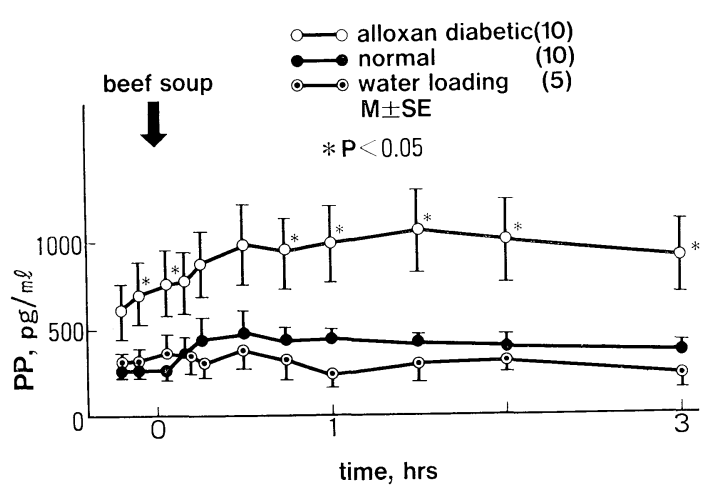

Fig. 2. Changes in plasma PP levels after beef soup or water ingestion. Statistical analysis was made on the difference between results for normal and diabetic dogs.

in the fasting state were $279 \pm 36 \mathrm{pg} / \mathrm{ml}$ and reached $461 \pm 147 \mathrm{pg} / \mathrm{ml} 30 \mathrm{~min}$ after loading, and these increases were significant at 60 $\min (\mathrm{p}<0.01), 90 \mathrm{~min}(\mathrm{p}<0.01), 120 \mathrm{~min}$ $(\mathrm{p}<0.05)$ and $180 \mathrm{~min}(\mathrm{p}<0.01)$ (Figure 2$)$. On the other hand, the plasma PP values in the diabetic dogs were $705 \pm 192 \mathrm{pg} / \mathrm{ml}$ in the fasting state and they went up to $871 \pm 187 \mathrm{pg} / \mathrm{ml}$ at $15 \mathrm{~min}(\mathrm{p}<0.01) 1,047$ $\pm 232 \mathrm{pg} / \mathrm{ml}$ at $90 \mathrm{~min}(\mathrm{p}<0.02)$ and $997 \pm$ $239 \mathrm{pg} / \mathrm{ml}$ at $120 \mathrm{~min}(\mathrm{p}<0.05)$ after ingestion of the soup. In comparison of the values in normal and alloxan diabetic dogs, the plasma PP values were significantly higher at $0,5,45,60,90$ and $120 \mathrm{~min}$ in the diabetic dogs $(\mathrm{p}<0.05)$. The plasma IRG values for normal dogs were $51 \pm 11$ $\mathrm{pg} / \mathrm{ml}$ at $0 \mathrm{~min}$ and they had increased significantly to $177 \pm 35 \mathrm{pg} / \mathrm{ml}$ by three hours ( $p<0.01$ at $180 \mathrm{~min}, \mathrm{p}<0.02$ at $15 \mathrm{~min}$ and $120 \mathrm{~min}, \mathrm{p}<0.05$ at $45 \mathrm{~min}$ and $90 \mathrm{~min}$ ) (Figure 3). In diabetic dogs the fasting plasma IRG levels were $237 \pm 47 \mathrm{pg} / \mathrm{ml}$ and they reached $292 \pm 72 \mathrm{pg} / \mathrm{ml}$ at $180 \mathrm{~min}$, but this increase was not significant. In comparison with the levels in normal dogs, the levels at $0,5,10,15,30$ and $45 \mathrm{~min}$ in diabetic dogs were quite high $(\mathrm{p}<0.05)$. When only water was administered, there was no increase in IRG levels. The plasma

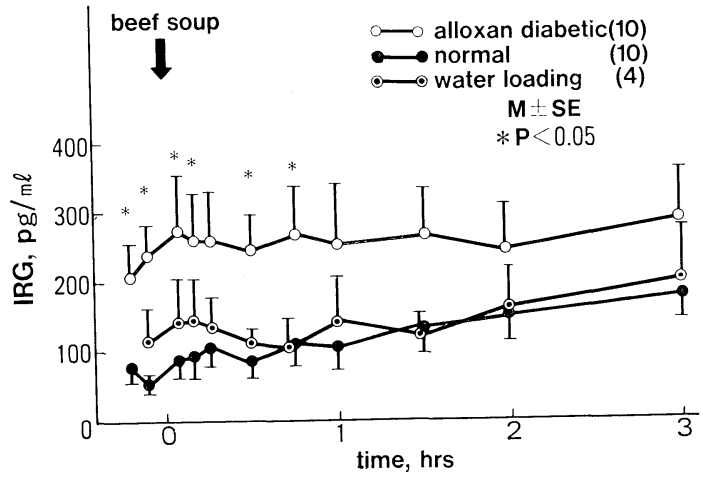

Fig. 3. Changes in plasma IRG levels after beef soup or water ingestion. Statistical analysis was made on the difference between results for normal and diabetic dogs.

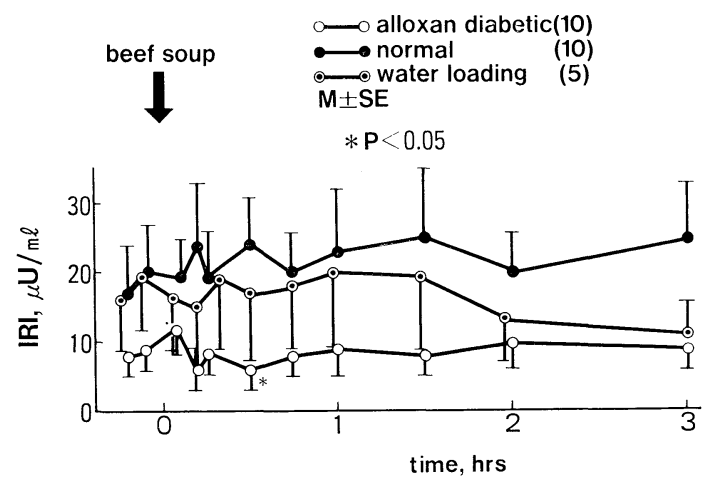

Fig. 4. Changes of plasma IRI levels after beef soup or water ingestion. Statistical analysis was made on the difference between results for normal and diabetic dogs.

IRI levels in normal dogs were $20 \pm 7 \mu \mathrm{U} / \mathrm{ml}$ in the fasting state and $25 \pm 10 \mu \mathrm{U} / \mathrm{ml}$ at $90 \mathrm{~min}$ (Figure 4). In diabetic dogs the fasting level of plasma IRI was $9 \pm 3 \mu \mathrm{U} / \mathrm{ml}$ and it did not change thereafter, the low level of insulin being maintained. The plasma $\Sigma$ glucose $(\Sigma \mathrm{G}), \Sigma$ PP, $\Sigma$ IRG and $\Sigma$ IRI during three hours of beef soup ingestion test were calculated (Figure 5). The plasma $\Sigma$ glucose, $\Sigma$ PP and $\Sigma$ IRG in the diabetic dogs were significantly higher than in the normal dogs $(\mathrm{p}<0.01$ or 0.05$)$. The plasma IRI was low in the diabetic dogs, 

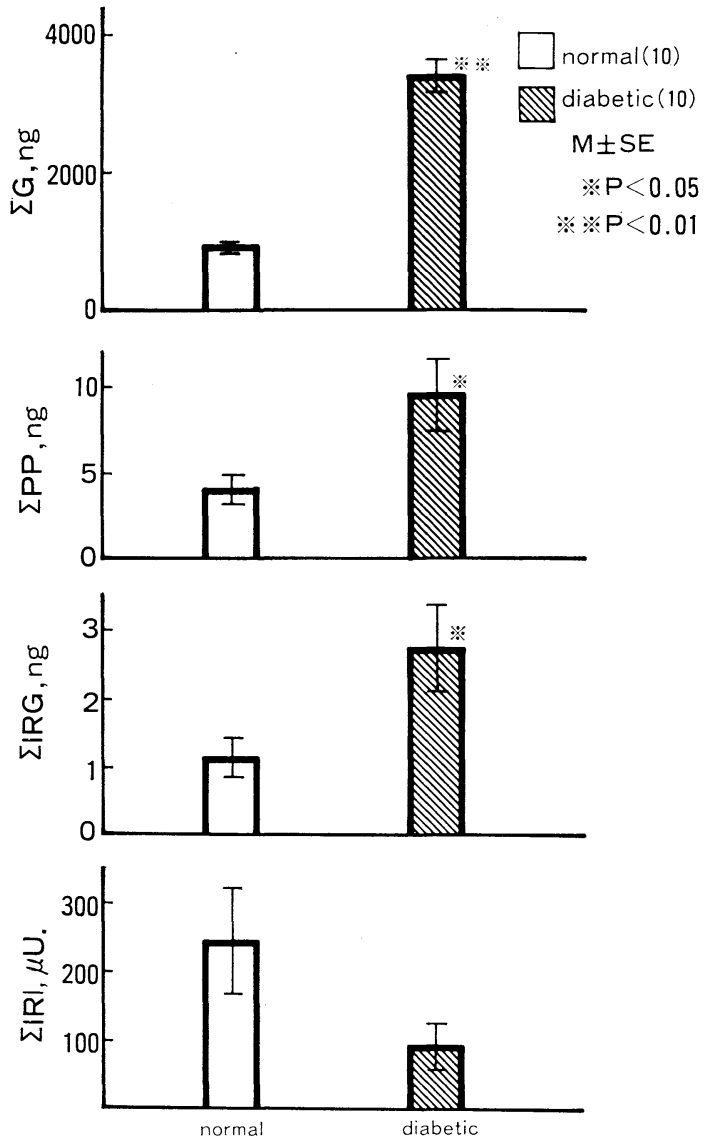

Fig. 5. Plasma glucose, PP, IRG and IRI during three hours of beef soup ingestion test.

but not significantly.

\section{IRI, PP and IRG Content in Normal and Alloxan Diabetic Dogs Pancreases}

The IRI content of the uncinate process, head, body and tail of the pancreas of normal and alloxan diabetic dogs was determined (Figure 6). The levels were $0.81 \pm$ $0.13,0.94 \pm 0.22,1.62 \pm 0.49$ and $1.73 \pm 0.5$ $\mathrm{U} / \mathrm{g}$, respectively, showing a gradual increase from the uncinate process to the tail of the pancreas in the normal dog. In dogs kept diabetic for four or twelve weeks they decreased markedly in all areas of the pancreas owing to the destruction of $\mathrm{B}$ cells and the values for the uncinate process and tail in

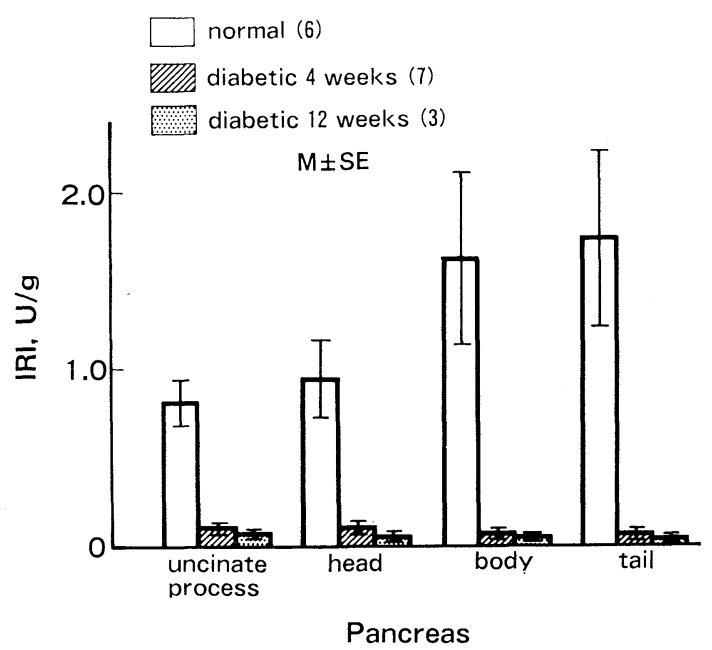

Fig. 6. Insulin content of pancreas in normal and alloxan diabetic dogs.

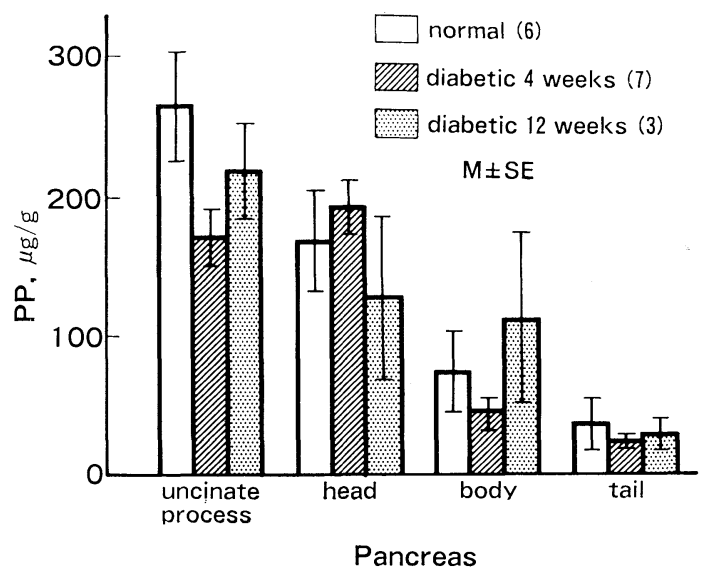

Fig. 7. PP content of pancreas in normal and alloxan diabetic dogs.

the former were $0.088 \pm 0.010$ and 0.046 $\pm 0.001 \mathrm{U} / \mathrm{g}$, respectively, only one tenth or one-fortieth of the values in normal dogs. Between alloxan diabetic dog groups, there were no significant differences.

The PP content of the uncinate process, body and tail of the normal dog pancreas was $264 \pm 40,73 \pm 29,35 \pm 19 \mu \mathrm{g} / \mathrm{g}$, respectively, and that of the alloxan diabetic dog pancreas for four weeks was $170 \pm 20 \mu \mathrm{g} / \mathrm{g}$ 
in the uncinate process, and $43 \pm 12 \mu \mathrm{g} / \mathrm{g}$ in the body and $20 \pm 3 \mu \mathrm{g} / \mathrm{g}$ in the tail (Figure 7). These value were not significantly different from those in normal dogs except for the low value in the uncinate process in the diabetic dog $(\mathrm{p}<0.05)$, and it could be concluded that there was no significant difference between normal and diabetic dogs

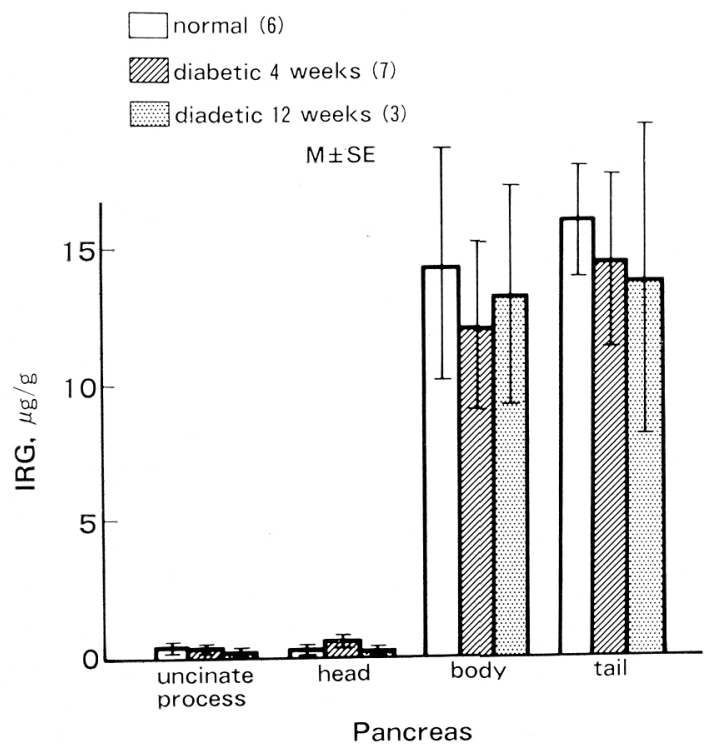

Fig. 8. IRG content of pancreas in normal and alloxan diabetic dogs. if we include the results for twelve week alloxan diabetic dogs. The results for IRG were the reverse of those with PP, the IRG content of the uncinate process of the normal dog being only $0.15 \pm 0.04 \mu \mathrm{g} / \mathrm{g}$, but the levels increased from body to tail, in which the levels were $14.30 \pm 4.25$ and 16.11 $\pm 2.12 \mu \mathrm{g} / \mathrm{g}$, respectively, revealing an outstanding difference in glucagon content (Figure 8). Similar values and regional differences were found in the diabetic dogs. The amounts of IRG in the uncinate process and tail in the four weeks diabetic dogs were $0.13 \pm 0.04 \mu \mathrm{g} / \mathrm{g}$ and $14.51 \pm 3.22 \mu \mathrm{g} / \mathrm{g}$, and these values were not significantly different from those in the normal dogs. Between diabetic dogs there was no significant difference.

\section{Immunocytochemical Studies}

Bouin-fixed, decerated, paraffin sections of dog pancreases were stained by the unlabeled antibody-enzyme method. The Bcells of pancreatic islets at the uncinate process in the diabetic dogs were strikingly decreased compared with those in the normal dogs (unpublished results). On the other hand, the PP-cells at the uncinate process (Figure 9, 10) were present similarly to those in the normal dogs.

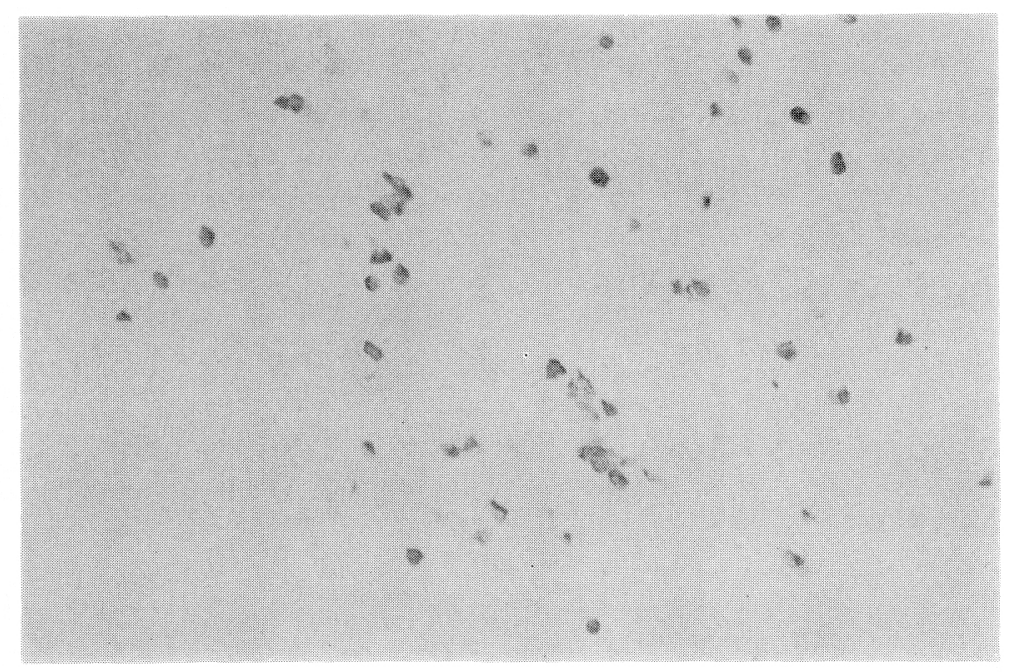

Fig. 9. An area of the uncinate process of the normal dog pancreas, in which the PP cells are stained black, $\times 80$. The PP cells were located in the islets and exocrine parts. 


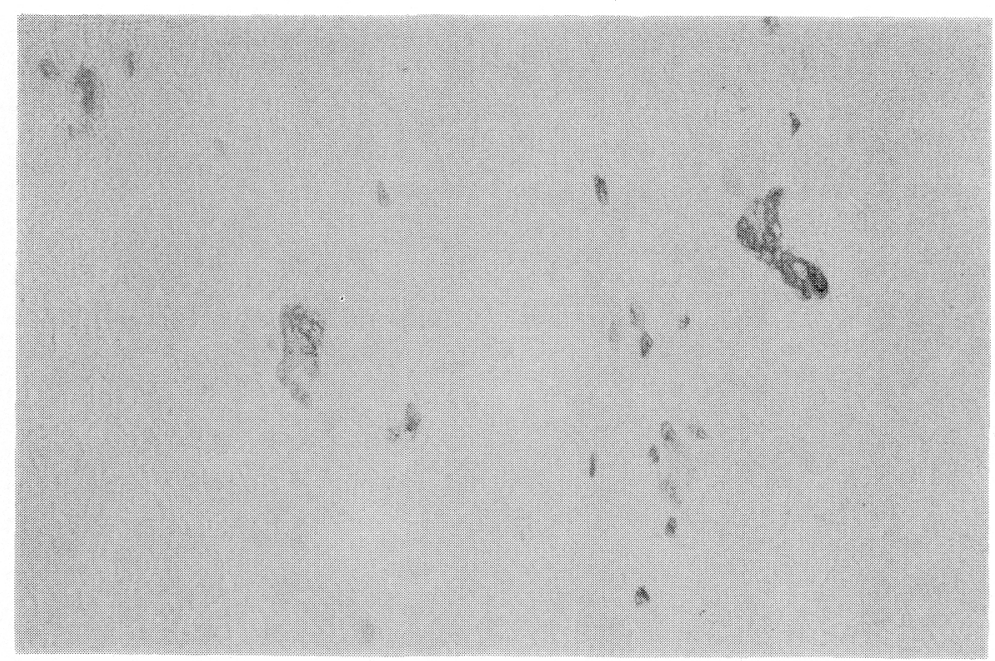

Fig. 10. An area of the uncinate process of the four weeks alloxan diabetic dog pancreas. Same staining and same magnification as Figure 9.

\section{Discussion}

The high plasma levels of PP and IRG seen in untreated diabetic subjects were demonstrated in the alloxan diabetic dogs. In human subjects the plasma PP responses after ingestion of beef soup assume a biphasic pattern, peaking initially at five to ten minutes and then dropping once and remaining at high levels thereafter (Inoue et al. unpublished results). Although the amount of beef soup administered in this study was three times as great as that given to human subjects and a significant increase in PP was observed, the plasma responses of PP after soup administration were not as strong in either kind of $\operatorname{dog}$ as in human subjects. Wilson et al. (1978) administered a protein meal to dogs, but could not find any sharp plasma PP increase and its maximum point was found at 60 to 90 minutes after administration. In this investigation, dogs were anesthetized with pentobarbital, which causes a hyperparasympathic state in dog (Dundee and Clarke, 1980), and might have some effects on PP secretion (Schwartz et al,, 1978; Guzman et al., 1981). The increase in plasma IRI after administration of the soup to normal dogs was also insidious compared with that in human subjects, peaking at three hours after the meal and this high level continued for many hours thereafter (Goriya et al, 1979). Therefore the difference in the plasma PP response pattern from that of human subjects could be due to some species difference in the materials. After beef soup administration, there was a significant change in the plasma glucose level only in normal dogs. This could be a reflection of the slightly significant change in plasma IRG levels in normal dogs. In diabetic dogs such increases in plasma glucose and IRG levels were not found. This would be due to the weak capacity for IRG secretion of beef soup administration. The plasma IRI levels in diabetic dogs were significantly lower than those in normal dogs, and there were no marked changes in IRI values in either group after beef soup administration. Insulin in the pancreas was most abundant in the tail portion just as reported in human subjects by Wrenshall et al. (1952) and Rastogi et al. (1973). The amount of insulin in alloxan diabetic dogs was very low, especially in the tail portion of the pancreas.

The regional distribution of pancreatic PP and IRG were in an inverse relationship. The amount of PP was high in the uncinate 
process and the head of the pancreas, and low in the body and tail, and these findings were consistent with the results of Gingerich et al. (1978) and Gersell et al. (1979). Orci et al. (1976) and Baetens et al. (1976) found morphologically, by the immunofluorescence technique, that PP-containing cells were abundant in the head and scarce in the body and tail of the rat pancreas and that, on the other hand, glucagon-containing cells were abundant in the body and tail of the pancreas. In this study, the glucagon content of the pancreas was very low in the uncinate process and the head and high in the body and head. Bencosme \& Liepa (1955) had already demonstrated it histologically, and similar results were reported thereafter (Gingerich et al., 1978; Gersell et al., 1979). In the embryonic development of pancreas of mammals including human subjects, it is believed that most of the pancreas derives from the dorsal primordium and its head from the ventral primordium (Picket and Rutter, 1972).

Although immunocytochemical studies were not done morphometrically, the distribution and the amounts of PP and IRG in the pancreas of alloxan diabetic dogs were not so different from those of normal dogs irrespective of the higher plasma response in diabetic dogs. Gepts et al. (1977) reported that pancreatic PP cells in autopsied juvenile diabetics are immunohistologically hyperplastic and that fact might be inconsistent with our results. However, Stefan et al. (1982) and Klöppel and Drenck (1983) found no increase in PP cells in the pancreas of Type 1 diabetics. The reason for this discrepancy is not clear, and it might be due to some difference in materials used. In this study, from the viewpoint of hormonal content and histological studies, no hyperplastic findings of PP cells were found in the alloxan diabetic dog's pancreas. Thus in the diabetic state PP or IRG is supposed to be easily secreted irrespective of its normal content. Further investigation on their biosynthesis or secretion would be necessary to elucidate their mechanism of secretion.

\section{Acknowledgement}

The authors are grateful to Prof. T. Fujita (Niigata University, School of Medicine, Department of Anatomy) for his advice and assistance in the histochemical studies.

\section{References}

Baetens, D., C. Rufener, and L. Orci (1976). Bovine pancreatic polypeptide (BPP) in the pancreas and in the gastro-intestinal tract of the dog. Experientia 32, 785.

Bencosme, J. A., and E. Liepa (1955). Regional differences of the pancreatic islet. Endocrionology 57, 588-593.

Bergen, D., J. C. Floyd and S. B. Pek (1981). The effect of treatment of type 2 (insulin independent) diabetes mellitus on plasma concentration of pancreatic polypeptide and glucagon. Diabetologia 21, 120-125.

Chance, R. E., N. E. Moon and M. G. Johnson (1979). Human pancreatic polypeptide (HPP) and bovine pancreatic polypeptide (BPP). In : Methods of Hormone Radioimmunoassay. 2nd edition. Jaffe, B. M., and Behrman, H. R., Eds. Academic Press, New York. PP. 657-672.

Dundee, J. W., and R. S. J. Clarke (1980). Noninhalational anaesthetics. In: General Anaesthesia. Volume 1. 4th edition. Gray, T. C., Nunn, J. F., and Utting, J. E., Eds. Butterworths \& Co., Ltd. London. pp. 217-271.

Floyd, J. D., S. S. Fajans, S. Pek and R. E. Chance (1977). A newly recognized pancreatic polypeptide; plasma levels in health and disease. Recent Progr. Horm. Res. 33, 519-570.

Gepts, W., J. D. Mey and M. Marichal-Pipelears (1977). Hyperplasia of " pancreatic polypeptide" cells in the pancreas of juvenile diabetes. Diabetologia 13, 27-34.

Gersell, D. J., R. L. Gingerich and M. H. Greider (1979). Regional distribution and concentration of pancreatic polypeptide in the human and canine pancreas. Diabetes 28, 11-15.

Gingerich, R. L., P. E. Lacy, R. E. Chance and M. G. Johnson (1978). Regional pancreatic 
concentration and in-vitro secretion of canine pancreatic polypeptide, insulin and glucagon. Diabetes 27, 96-101.

Goriya, Y., A. Bahoric, E. B. Marliss, B. Zinman and A. M. Albisser (1979). Glycemic regulation using a programmed insulin delivery device. III. Long-term studies on diabetic dogs. Diabetes 28, 558-564.

Guzman, S., J. Lonovics, P. G. Devitt, K. E. Hejtmancik, P. L. Rayford and J. C. Thompson (1981). Hormone-stimulated release of pancreatic polypeptide before and after vagotomy in dogs. Am. J. Physiol. 240, G114G121.

Hayashi, M., J. C. Floyd, Jr., S. Pek and S. S. Fajans (1977). Insulin, proinsulin, glucagon and gastrin in pancreatic tumors and in plasma of patients with organic hyperinsulinism. $J$. Clin. Endocrinol. Metab. 44, 681-694.

Henquin, J. C., P. Malvaux and A. E. Lambert (1974). Glucagon immunoassay using polyethylene glycol to precipitate antibody-bound hormone. Diabetologia 10, 61-68.

Klöppel, G., and C. R. Drenck (1983). Immunozytochemische morphometrie beim TypeI and Type-II diabetes mellitus. Deutsch. med. Wscnr. 108, 188-189.

Morgan, C. R., and M. A. Lazarow (1963). Immunoassay of insulin; two antibody system plasma insulin levels of normal, subdiabetic and diabetic rats. Diabetes 12, 115-126.

Orci, L., D. Baetens, M. Ravazzola, Y. Stefan and F. Malaisse-Lagae (1976). Pancreatic polypeptide and glucagon; non-random distribution in pancreatic islets. Life Science 19, 1811-1816.

Picket, R., and W. J. Rutter (1972). Development of the embryonic endocrine pancreas. In: Handbook of Physiology. section 7. Endocrinology. Vol. 1. American Physiological Society, Ed. Waverly Press, Baltimore. PP 25-60.

Rastogi, G. K., M. K. Shinha and R. J. Dash (1973). Insulin and proinsulin content of pancreases from diabetic and nondiabetic subjects. Diabetes 22, 804-807.

Schwartz, T. W., J. J. Holst, J. Fahrenkrug, S. L. Jensen, O. V. Nielsen, J. F. Rehfeld, O. B. S. DeMuckadell and F. Stadil (1978). Vagal, cholinergic regulation of pancreatic polypeptide secretion. J. Clin. Invest. 61, 781789.

Skare, S., K. F. Hanssen and G. Lundquist (1980). Increased plasma pancreatic polypeptide (PP) in diabetic ketoacidosis; normalization following treatment. Acta Endocrinologia 93, 466469.

Stefan, Y., L. Orci, F. Malaine-Lagae, A. Perrelet, Y. Patel and R. H. Unger (1982). Quantitation of endocrine cell content in the pancreas of nondiabetic and diabetic humans. Diabetes 31, 694-700.

Tasaka, Y., S. Inoue, Y. Hirata, F. Hanyu and M. Endo (1981). Time course of content of insulin, glucagon and pancreatic polypeptide in human pancreatic tissue obtained by surgery. Endocrinol. Jpn. 28, 261-264.

Tasaka, Y., S. Inoue, K. Marumo and Y. Hirata (1983). Pancreatic polypeptide and insulin content in diabetic and nondiabetic human pancreas and their relationship to the stability of the fasting serum glucose. Tohoku J. exp. Med. 141, 443-450.

Tsuda, K., H. Sakurai, Y. Seino, S. Seino, K. Tanigawa, H. Kuzuya, K. Mori and H. Imura (1980). Abnormal pancreatic polypeptide response to oral glucose loading in diabetes mellitus. Clinical Endocrinology 13, 425-429.

Wilson, R. M., G. Boden and O. E. Owen (1978). Pancreatic polypeptide responses to a meal and to intraduodenal amino acids and sodium oleate. Endocrinology 102, 859-863.

Wrenshall, G. A., A. Bogoch and R. C. Ritchie (1952). Extractable insulin of pancreas. Correlation with pathological and clinical findings in diabetic and nondiabetic cases. Diabetes 1, 87-107. 